\title{
Upper Atmospheric Monitoring for Ares I-X Ascent Loads and Trajectory Evaluation on the Day-of-Launch
}

\author{
Barry C. Roberts ${ }^{1}$ \\ NASA, Marshall Space Flight Center \\ Kevin McGrath \\ Jacobs Engineering, ESTS Group \\ Brett Starr, Jay Brandon \\ NASA, Langley Research Center
}

In 2009 the National Aeronautics and Space Administration plans to launch the Ares I-X vehicle. This will be the first test of the Ares launch vehicle in the Constellation Program. Part of the program, whose eventual purpose is to return humans to the Moon, is to build a new manned launch vehicle, called the Ares I. The Ares I-X vehicle emulates the outer mold line of Ares I. The first stage has a four-segment Solid Rocket Booster, of Space Shuttle heritage, and a dummy fifth segment. The second stage consists of the dummy Ares I second stage, a dummy Orion capsule and a dummy Ares I launch abort system. On the day-of-launch of the Ares I-X, the ascent loads and vehicle control systems will have to be evaluated to ensure a safe and successful flight. This will be performed by Langley Research Center (LaRC). Part of the support of the trajectory evaluation during the launch countdown will include monitoring of the upper atmospheric winds and thermodynamic properties by Marshall Space Flight Center's Natural Environments Branch. This includes an independent verification of the wind profiles being used for trajectory evaluation.

On the day-of-launch of the Ares I-X, the vehicle will be protected by evaluating the loads generated by running the trajectory through the wind profile measured during the countdown, against a pre-defined loads placard. Vehicle ascent loads will be calculated during the launch countdown and assessed against structural design constraints. A flight load indicator (FLI) will be used to quantify day-of-launch ascent loads as a percentage of allowable load at each station along the length of Ares I-X

The Ares I-X trajectory performance will also be assessed to verify that flight related requirements are met. The assessment will include evaluation of the control power margin, the gimbal rate limit margin, and the thrust vector control deflection duty cycle.

An important part of the trajectory evaluation on day-of-launch will be the monitoring of the upper atmospheric thermodynamic and wind conditions. The atmospheric winds and thermodynamic properties will be measured during the launch countdown using the Automated Meteorological Profiling System's (AMPS) Low-Resolution Flight Element (LRFE). The LRFE consists of a latex weather balloon with a radiosonde attached. The radiosonde measures the atmospheric temperature and relative humidity, determines its position using the Global Positioning System, and then transmits the data to the AMPS processing system on the ground. The first LRFE release at $6 \mathrm{hr} 30 \mathrm{~min}$ prior to launch (L-6:30) will be used to help develop a launch upper air winds forecast by the Spaceflight Meteorology Group at Johnson Space Flight Center. This forecast will be sent to Marshall Space Flight Center's Natural Environments Branch (known on launch day as Marshall Winds) at L-4:45 to be evaluated against the mean and 99\% wind profile for the month the launch occurs. The mean and $99 \%$ wind profiles are derived using Earth 
Global Reference Atmospheric Model 2007. This data will be provided to support a commit-to-launch decision that is planned prior to the start of the $4 \mathrm{hr}$ countdown. If the forecast winds approach or exceed the $99 \%$ wind profile the launch may be delayed to achieve winds closer to the mean wind profile to ensure the safety of the vehicle.

Once the launch countdown has begun, four LRFE's are planned to be released at L3:50, L-2:50, L-1:50 and L-:50. It takes approximately one hour for the LRFE to reach the desired altitude of $25 \mathrm{~km}$ (82kft) with an extra 10 minutes added for quality control processing time. Wind profiles from these balloons will go to both the Marshall Winds and LaRC. Marshall Winds will plot the wind profile against the April mean and $99 \%$ wind profile and forward it to LaRC. They will also verify the wind data from the LRFE's is valid by comparing it to wind profiles produced by the Kennedy Space Center (KSC) $50 \mathrm{MHz}$ Doppler Radar Wind Profiler (50DRWP). The 50DRWP produces wind profiles up to $18.6 \mathrm{~km}(61.0 \mathrm{kft})$ approximately every 5 minutes. Wind profiles from the 50DRWP will be monitored beginning at L-4 hours. The comparison of the LRFE to the 50DRWP data will be performed by plotting them together. A 50DRWP wind profile generated near the mid-point in time of the LRFE flight is used for the validation of the LRFE data. This is an objective comparison used to show if there are any significant deviations between the LRFE and the 50DRWP. Since the 50DRWP produces a wind profile every 5 minutes, there are many 50DRWP profiles made during the time it takes to produce one LRFE wind profile. Thus any significant error in the LRFE data would be obvious against the multiple 50DRWP wind profiles.

The evaluation of the each LRFE wind profile will be performed by Marshall Winds and sent to the LaRC trajectory lead at KSC.

The wind and thermodynamic profile from the LRFE released nearest to the Ares I-X launch time will be archived and used for Ares I-X post-flight evaluation since this will be the closest planned measured profile to launch time. In the event the Ares I-X launch is delayed until sometime later in the launch window, LRFE's will continue to be released every hour. The data will be evaluated as shown above and the LRFE closest to the actual launch time will be used for the post flight evaluation.

${ }^{1}$ NASA, Marshall Space Flight Center

Mail Code: EV44

Huntsville, AL 35812

barry.c.roberts@nasa.gov

Phone: 256-544-6053

Fax: 256-544-0242

Submitted for 1st AIAA Atmospheric and Space Environments Conference 


\title{
Upper Atmospheric Monitoring for Ares I-X Ascent Loads and Trajectory Evaluation on the Day-of-Launch
}

\author{
Barry C. Roberts* \\ NASA Marshall Space Flight Center, Huntsville, AL, 35812 \\ Kevin McGrath \\ Jacobs Engineering ESTS Group, Huntsville, ,AL 35812 \\ and \\ Brett Starr ${ }^{\dagger}$, Jay Brandon \\ NASA Langley Research Center, Hampton, VA, 23681
}

\begin{abstract}
During the launch countdown of the Ares I-X test vehicle, engineers from Langley Research Center will use profiles of atmospheric density and winds in evaluating vehicle ascent loads and controllability. A schedule for the release of balloons to measure atmospheric density and winds has been developed by the Natural Environments Branch at Marshall Space Flight Center to help ensure timely evaluation of the vehicle ascent loads and controllability parameters and support a successful launch of the Ares I-X vehicle.
\end{abstract}

\section{Nomenclature}

50DRWP $=50 \mathrm{MHz}$ Doppler Radar Wind Profiler

AMPS $=$ Automated Meteorological Profiling System

$\mathrm{CEV}=$ Crewed Exploration Vehicle

$\mathrm{CM}=$ Command Module

DOL = Day-of-Launch

FLI $=$ Flight Load Indicator

GRAM = Global Reference Atmospheric Model

GPS $=$ Global Positioning System

HRFE $=$ High Resolution flight Element

JSC $=$ Johnson Space Center

LAS $=$ Launch Abort System

LRFE = Low Resolution Flight Element

$\mathrm{KSC}=$ Kennedy Space Center

LaRC $=$ Langley Research Center

MLD $=$ Maximum Likely Dispersion

MSFC $=$ Marshall Space Flight Center

RoCS $=$ Roll Control System

$\mathrm{SA}=$ Spacecraft Adapter

$\mathrm{SM}=$ Service Module

SMG = Spaceflight Meteorology Group

$\mathrm{SRD}=$ Systems Requirements Document

STEL = Static Elastic Load

TVC $=$ Thrust Vector Control

\section{Introduction}

In 2009 the National Aeronautics and Space Administration plans to launch the Ares I-X flight test vehicle at Kennedy Space Center (KSC) Launch Complex 39B. This will be the first test launch vehicle in the

${ }^{*}$ Flight Vehicle Atmospheric Environments, Natural Environments Branch, EV44, AIAA Senior Member.

${ }^{\dagger}$ Aerospace Engineer, Vehicle Analysis Branch, E401. 
Constellation Program. Part of the program, whose eventual purpose is to return humans to the Moon, is to build a new manned launch vehicle, called the Ares I. The Ares I-X vehicle emulates the outer mold line of Ares I. The first stage simulator (Figure 1) has an aft booster assembly, a four-segment Solid Rocket Booster, of Space Shuttle heritage, and a dummy fifth segment. The second stage simulator consists of the dummy Ares I liquid second stage, Interstage $1 \&$ 2, a Roll Control System (RoCS) and a Spacecraft Adapter (SA). The Crewed Exploration Vehicle (CEV) simulator has a dummy Service Module (SM), Command Module (CM) and a Launch Abort System (LAS).

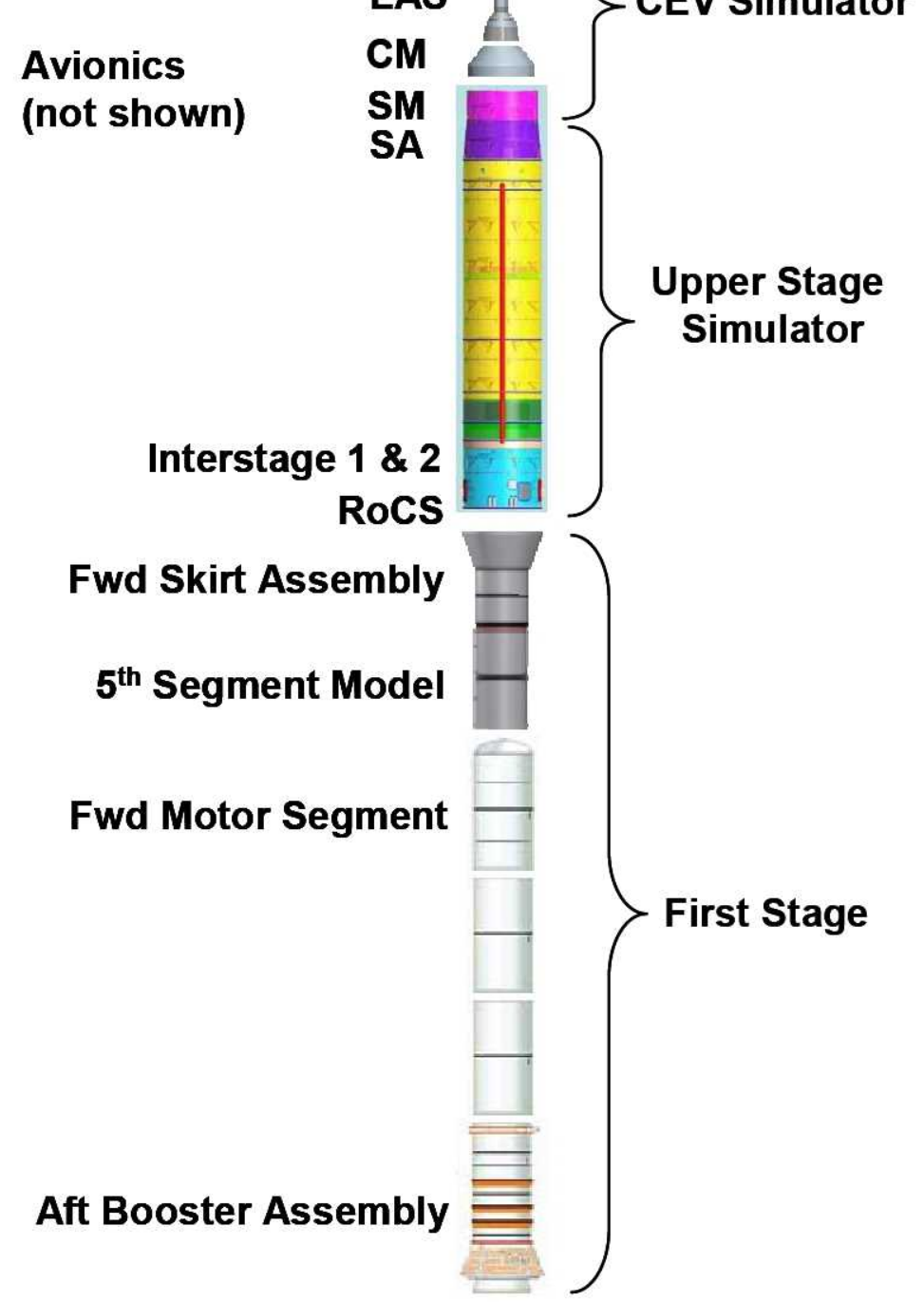

Figure 1. The Ares I-X Vehicle. 
On the Day-of-Launch (DOL) of the Ares I-X vehicle, the ascent loads and vehicle control systems will have to be evaluated to ensure a safe and successful flight. This will be performed by Langley Research Center (LaRC). Part of the support of the trajectory evaluation during the launch countdown will include monitoring of the upper atmospheric winds and thermodynamic properties by Marshall Space Flight Center's Natural Environments Branch. This includes an independent verification of the wind profiles being used for trajectory evaluation.

The intent of this paper is to give a description of the trajectory design method, and plans for trajectory evaluation and upper atmospheric wind and thermodynamic modeling for Ares I-X vehicle.

\section{Vehicle Loads Assessment}

On DOL, Ares I-X vehicle structural loads and performance assessments will be performed for measured winds aloft using a vehicle ascent simulation. Loads assessments will be made using a Flight Load Indicator (FLI) which quantifies DOL ascent loads as a percentage of allowable load at each station along the length of the vehicle. Performance assessments will be based on the Ares I-X Systems Requirements Document (SRD) requirements for Mach-dynamic pressure relationship, heading and separation conditions.

The FLI used in the loads assessments is defined as the ratio of DOL load to the vehicle's design load limit at each station along the length of the Ares I-X. An FLI $\leq 1.0$ at each vehicle station indicates ascent loads are at or below the vehicle's structural capability and the Ares I-X is GO for launch. The DOL load, $\mathrm{L}_{\mathrm{DOL}}$, is composed of a coupled loads component, $\mathrm{L}_{\mathrm{CL}}$, a load persistence component, $\mathrm{L}_{\mathrm{P}}$, and a margin component, $\mathrm{L}_{\mathrm{M}}$, as shown in Equation 1.

$$
L_{D O L}=L_{C L}+L_{P}+L_{M} \quad \text { Equation } 1
$$

$\mathrm{L}_{\mathrm{CL}}$ is a combination of the static elastic load (STEL) due to DOL winds and dynamic loads due to buffet, First Stage thrust oscillation, RoCS thrust, and tuned wind gusts. STEL is calculated in the ascent simulation using the DOL winds. The dynamic loads are not a function of DOL winds and hence are not calculated on day of launch but are instead taken from the Ares I-X coupled loads analysis. The individual dynamic loads are combined using the coupled loads analysis "loads combination equation" and tabulated as a single composite dynamic load that is a function of time. The tabulated values are stored in the simulation and combined with the calculated STEL load to yield $\mathrm{L}_{\mathrm{CL}}$.

The load persistence, $\mathrm{L}_{\mathrm{P}}$, accounts for variations in $\mathrm{L}_{\mathrm{CL}}$ attributable to temporal uncertainty of the wind profile change during the hours before launch. In addition, since high frequency components of the wind profile tend to be in-persistent hours before launch, a low-pass filtered version of the measured profile is used in pre-launch trajectory simulations. The combined effects of temporal variability and wind profile filtering are included in the methodology for determination of $\mathrm{L}_{\mathrm{p}}$. The effects will be calculated prior to day of launch using historical wind pairs data. Wind pairs data consist of wind profiles measured 3.5 hours and 2.0 hours apart. A low-pass filter developed by the Marshall Space Flight Center (MSFC) Natural Environments Branch is applied to the first profile in the pair to remove wind features that will tend to not persist from measurement time till launch. The filter cutoff frequency is based on the length of time between balloon measurements, as developed by Spiekermann et $\mathrm{al}^{1}$. The second wind profile in each pair is unfiltered and contains the high frequency wind structure removed from DOL balloons. $\mathrm{L}_{\mathrm{CL}}$ is calculated for the filtered and unfiltered winds in each pair, and the difference in $\mathrm{L}_{\mathrm{CL}}$ are fit to an extreme value distribution. $\mathrm{L}_{\mathrm{P}}$ is then defined to be the 3-sigma value of the difference in $\mathrm{L}_{\mathrm{CL}}$ from that distribution.

The load margin, $\mathrm{L}_{\mathrm{M}}$, accounts for changes in $\mathrm{L}_{\mathrm{CL}}$ due to known uncertainties in the model data used in the Ares $\mathrm{I}$-X simulation such as aerodynamic coefficient, mass, and propulsion uncertainties. $\mathrm{L}_{\mathrm{M}}$ is calculated prior to day of launch. The effect of system dispersions on $\mathrm{L}_{\mathrm{CL}}$ is a function of winds. As a result, system dispersion effects must be determined for randomly dispersed winds and the system dispersion effect on $\mathrm{L}_{\mathrm{CL}}$, isolated from wind effects. To accomplish this, two Monte Carlo analyses are performed. One with system dispersions and randomly dispersed winds, and another with the same randomly dispersed winds, but no system dispersions. The effect of systems dispersion on $\mathrm{L}_{\mathrm{CL}}$ is fit to and extreme value distribution and $\mathrm{L}_{\mathrm{M}}$ is defined to be the 3-sigma value of that distribution. 
As wind profiles become available from balloon data, $\mathrm{L}_{\mathrm{CL}}$ is calculated throughout the ascent and the precalculated values of $\mathrm{L}_{\mathrm{P}}$ and $\mathrm{L}_{\mathrm{M}}$ are added to it to determine $\mathrm{L}_{\mathrm{DOL}}$.

The performance of a nominal Ares I-X will be assessed using the Mach-dynamic pressure relationship, heading, and separation conditions predicted from the Ares I-X ascent simulation. The Ares I-X is GO for launch if the heading, dynamic pressure vs. Mach number relationship, and separation dynamic pressure are within the Ares I-X $\mathrm{SRD}$ specifications. The SRD requirements are for a nominal vehicle thus the effects due to dispersions in vehicle mass, propulsion, aerodynamics, etc. are not included in this assessment.

\section{Vehicle Ascent Controllability Assessment}

A standoff from the maximum Thrust Vector Control (TVC) control deflection limits has been developed based on Monte Carlo assessments of dispersions on TVC deflection activity. This standoff was calculated based on computing pre-determined variations of TVC commands from 2000 Monte Carlo runs where winds were based on mean conditions for the month of launch, but with all other vehicle dispersions in the analysis, along with another 2000 Monte Carlo runs with the same system dispersions, but also with wind dispersions. These two sets of data were needed to evaluate the effects of system dispersions, and the effect of winds on system dispersions.. Additional analysis to determine pre-determined variations of TVC command variation due to wind persistence was conducted using measured wind pairs from Jimsphere balloon data in the summer and transition seasons. The Monte Carlo bounds and the additional variation due to the wind persistence are added together and result in the Maximum Likely Dispersion (MLD) of TVC commands. This MLD is then subtracted from the maximum Ares I-X command limit to determine the standoff bounds acceptable for DOL evaluations. The condition for acceptable control power margin using DOL measured winds will be that the predicted Ares I-X deflection limit remains below the standoff limits from launch to separation time minus $3 \mathrm{sec}$.

A standoff from the maximum rock and tilt rate limits has been developed based on Monte Carlo assessments of dispersions on the Ares I-X deflection activity. This standoff was calculated based on computing pre-determined variations of rock and tilt actuator rates from 2000 Monte Carlo runs where winds were based on mean conditions for the month of launch, but with all other vehicle dispersions in the analysis, along with another 2000 Monte Carlo runs with the same system dispersions, but also with wind dispersions. These two sets of data were needed to evaluate the effects of system dispersions, and the effect of winds on system dispersions. Additional analysis to determine pre-determined variations of actuator rate variation due to wind persistence was conducted using measured wind pairs from Jimsphere balloon data in the summer and transition seasons. The Monte Carlo bounds and the additional variation due to the wind persistence are added together and result in the MLD of TVC actuator rates. This MLD is then subtracted from the maximum actuator rate limit to determine the standoff bounds acceptable for DOL evaluations. The condition for acceptable control power margin using DOL measured winds will be that the predicted TVC rate limits remain below the standoff limits from launch to separation time minus 3 sec.

A standoff from the maximum allowable body-axis pitch and yaw rate limits for stage separation has been developed based on Monte Carlo assessments of dispersions on body-axis rate at stage separation. This standoff was calculated based on computing pre-determined variations of pitch and yaw rates from 2000 Monte Carlo runs where winds were based on mean conditions for the month of launch, but with all other vehicle dispersions in the analysis, along with another 2000 Monte Carlo runs with the same system dispersions, but also with wind dispersions. These two sets of data were needed to evaluate the effects of system dispersions, and the effect of winds on system dispersions. Additional analysis to determine pre-determined variations of pitch and yaw rate variation due to wind persistence was conducted using measured wind pairs from Jimsphere balloon data in the summer and transition seasons. The Monte Carlo bounds and the additional variation due to the wind persistence are added together and result in the MLD of body-axis pitch and yaw rates. This MLD is then subtracted from the maximum allowable body-axis rates at stage separation to determine the standoff bounds acceptable for DOL evaluations. The condition for acceptable stage separation body rates using DOL measured winds will be that the predicted body-axis rate limits remain below the standoff limits at the predicted stage separation time. 
A standoff from the maximum allowable Shuttle limit of TVC deflection duty cycle has been developed based on Monte Carlo assessments of dispersions on duty cycle calculations. This standoff was calculated based on computing pre-determined variations of TVC duty cycle from 2000 Monte Carlo runs where winds were based on mean conditions for the month of launch, but with all other vehicle dispersions in the analysis, along with another 2000 Monte Carlo runs with the same system dispersions, but also with wind dispersions. These two sets of data were needed to evaluate the effects of system dispersions, and the effect of winds on system dispersions. Additional analysis to determine pre-determined variations of duty cycle variation due to wind persistence was conducted using measured wind pairs from Jimsphere balloon data in the summer and transition seasons. The Monte Carlo bounds and the additional variation due to the wind persistence are added together and result in the MLD of TVC deflection duty cycle. This MLD is then subtracted from the maximum allowable TVC deflection duty cycle at stage separation to determine the standoff bounds acceptable for DOL evaluations. The condition for acceptable TVC deflection duty cycle using DOL measured winds will be that the predicted TVC deflection duty cycle remains below the standoff limits at the end of flight (or stage separation).

\section{Plans for Day-of-Launch Upper Atmospheric Monitoring}

An important part of the trajectory evaluation on day-of-launch will be the monitoring of the upper atmospheric thermodynamic and wind conditions. The atmospheric winds and thermodynamic properties will be measured during the launch countdown using the Automated Meteorological Profiling System's (AMPS) Low-Resolution Flight Element (LRFE). The LRFE consists of a latex weather balloon with a radiosonde attached. They are launched from the Cape Canaveral Weather Station located approximately $5 \mathrm{~km}$ from the location of the Ares I-X launch site at KSC Launch Complex 39B. The radiosonde measures the atmospheric temperature and relative humidity, determines its position using the Global Positioning System (GPS), and then transmits the data to the AMPS processing system on the ground. A proposed schedule of LRFE releases to support the FTV launch countdown is shown in Figure 2. The first LRFE release at $7 \mathrm{hr}$ prior to launch (L-7:00) will be used by the Spaceflight Meteorology Group (SMG) at Johnson Space Flight Center (JSC), along with atmospheric forecast models, to develop a launch time upper air winds forecast.

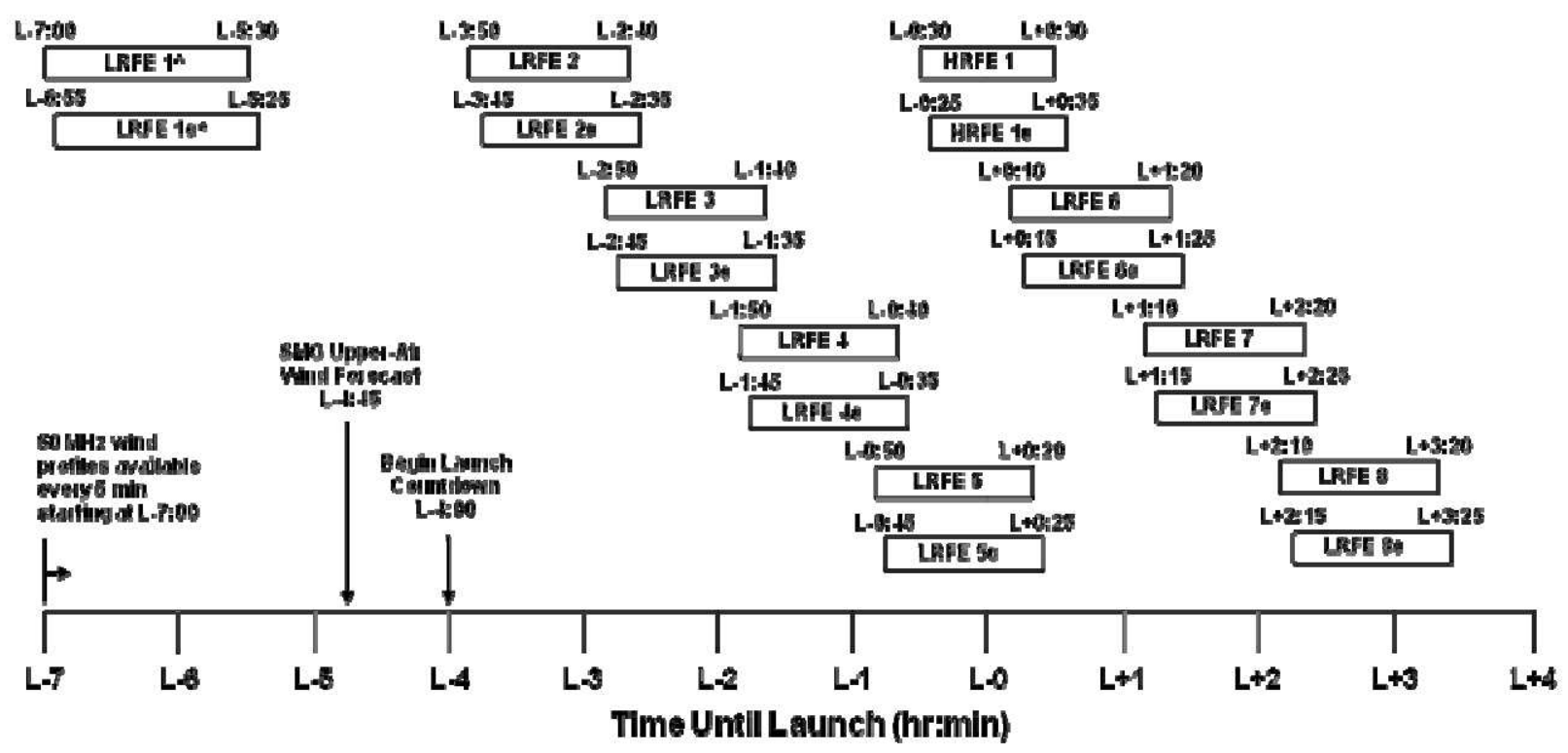

Figure 2. The proposed balloon schedule for the Ares I-X launch countdown. 
LRFE 1 will also be used to derive the atmospheric density profile, up to $24 \mathrm{~km}$ ( $80 \mathrm{kft}$ ), that will be used in the inflight loads and control simulations during the countdown. This forecast will be sent to MSFC Natural Environments Branch (known on launch day as Marshall Winds) at L-4:45 to be evaluated against observed wind from the L-7 hr LRFE and the mean and 95\% wind profile for the month the launch occurs. The mean and 95\% wind profiles are derived using Earth Global Reference Atmospheric Model (GRAM) 2007 and are shown in Figure 3. This data will be provided to support a commit-to-launch decision that is planned prior to the start of the $4 \mathrm{hr}$ countdown. For example, if the forecast winds exceeded the $95 \%$ wind profile, the launch could be delayed to achieve winds closer to the mean wind profile to ensure the safety of the vehicle.

Once the launch countdown has begun, LRFE's are planned to be released every hour, beginning at L-3:50, and through the $4 \mathrm{hr}$ launch window, if required. Backup balloons, denoted by " $\alpha$ ", will be launched 5 min after the primary in case there is a problem with the primary balloon, and the data cannot be used. It takes approximately one hour for the LRFE to reach the desired altitude of $20 \mathrm{~km}(65 \mathrm{kft})$ with an extra 10 minutes added for quality control processing time. This balloon launch schedule will ensure that a minimum of one good profile will be available for evaluation of flight loads and controllability check within $3 \mathrm{hr}$ of launch.

Wind profiles from these balloons will go to Marshall Winds, JSC SMG, and the ascent loads and controllability evaluation team located at KSC. Marshall Winds will verify the wind data from the LRFE's by comparing it to wind profiles produced by the KSC $50 \mathrm{MHz}$ Doppler Radar Wind Profiler (50DRWP). The 50DRWP produces wind profiles up to $18.6 \mathrm{~km}(61.0 \mathrm{kft})$ approximately every 5 minutes. A 50DRWP wind profile generated near the mid-point in time of the LRFE flight is used for the validation of the LRFE data. This is an objective comparison used to show if there are any significant deviations between the LRFE and the 50DRWP. Since the 50DRWP produces a wind profile every 5 minutes, there are many 50DRWP profiles made during the time it takes to produce one LRFE wind profile. Thus any significant error in the LRFE data would be obvious against the multiple 50DRWP wind profiles. Wind profiles from the 50DRWP will be monitored beginning at L-7 hrs. An example of an upper air winds forecast, and measured LRFE and 50DRWP wind profiles plotted against the GRAM 2007 mean and $95 \%$ envelopes is shown in Figure 3.

The JSC SMG will use the LRFE profiles to evaluate the upper air wind forecast provided at L- 4:45 hrs and provide an update to the forecast if needed.
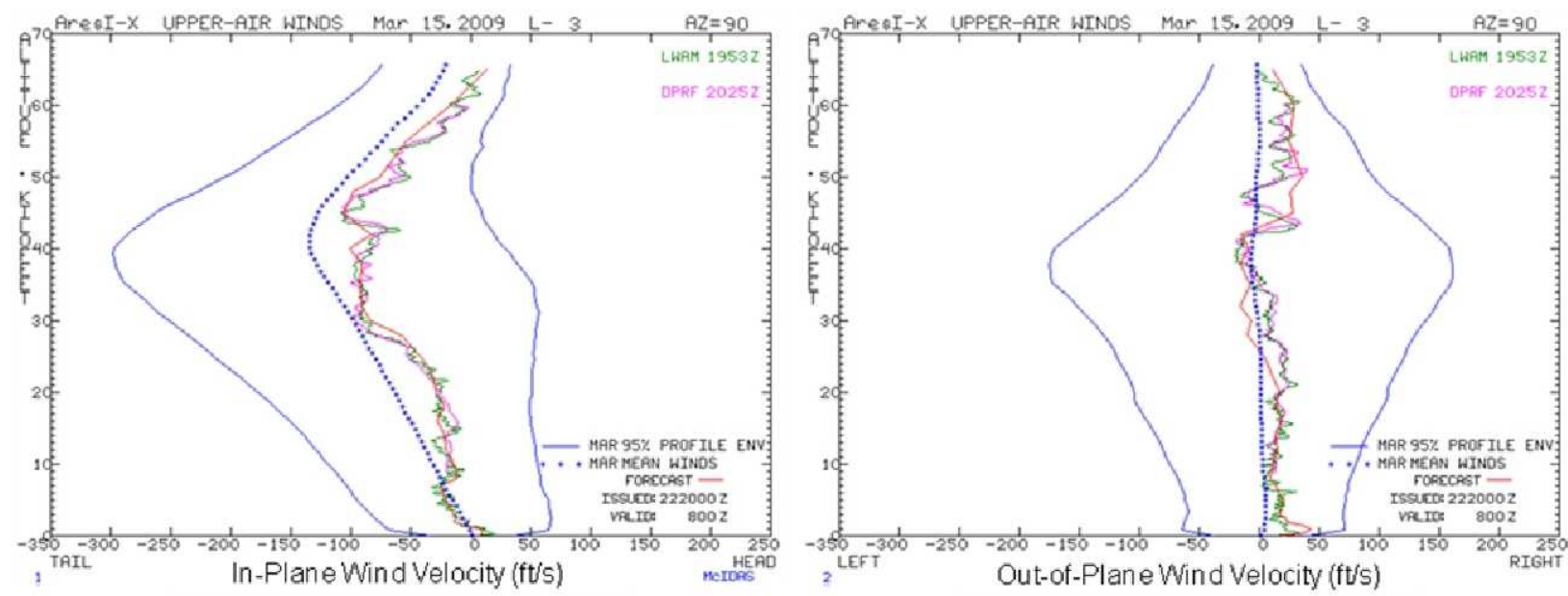

Figure 3. An example of an upper air wind forecast and measured profiles from the month of March plotted against the mean and 95 percentile $U$ and $V$ wind component envelopes derived from Earth GRAM 2007. 
The ascent loads and controllability team lead by LaRC will be located at KSC and will receive the wind profile from each LRFE. The wind profiles, along with the density profile obtained from the L-7:00 hr LRFE will be used to evaluate ascent loads and controllability as described above. After each evaluation they will report the results to the Ares I-X launch team.

A High Resolution Flight Element (HRFE) primary and backup balloon are planned to be launched approximately 30 min prior to the Ares I-X launch. The HRFE uses GPS-tracked Jimsphere balloons and the AMPS ground processor to record wind profiles in $30.5 \mathrm{~m}$ (100 ft) height increments up to approximately $16 \mathrm{~km}(52 \mathrm{kft})$. The HRFE wind profile, combined with the thermodynamic and wind (above the maximum altitude of the HRFE profile) profile from the LRFE released nearest to the Ares I-X launch, will be archived and used for Ares I-X post-flight evaluation. This "final meteorological" profile is used for post flight evaluations since this will be the closest measured profile to launch time and will best represent the actual conditions the vehicle flew through.

\section{Conclusion}

During the launch countdown of the Ares I-X test vehicle, the vehicle ascent loads and controllability will be evaluated using upper air density and wind measurements. A schedule for balloon releases from the Cape Canaveral Weather Station has been developed to provide these upper air density and wind measurements to ensure accurate and timely evaluation of the vehicle ascent loads and controllability by LaRC engineers and help ensure a successful launch of the Ares I-X test vehicle.

\section{Acknowledgments}

Contributions to this effort were also provided by Frank Leahy/NASA, Dr. Stanley Adelfang/Stanley Associates and Robert E. Barbré, Jr./Jacobs Engineering ESTS Group in the MSFC Natural Environments Branch/EV44.

\section{References}

\footnotetext{
${ }^{1}$ Spiekermann, C. E., Sako, B. H., and Kabe, A. M., "Identifying Slowly Varying and Turbulent wind Features for Flight
} Loads Analysis," Journal of Spacecraft and Rockets, Vol. 37, No. 4, 2000, pp. 426-433. 
Upper Atmi sheric Monitoring for Ares I-X Ascen W ad wil Trajectory Evaluation on th

Barry Roberts / NASA-MSE Kevin McGrath / Jacobs-MS Brett Starr/ NASA-LaRC Jay Brandon/NASA-LaRC

$1^{\text {st }}$ AIAA Atmospheric \& Space Environmẹnts Conferehlce

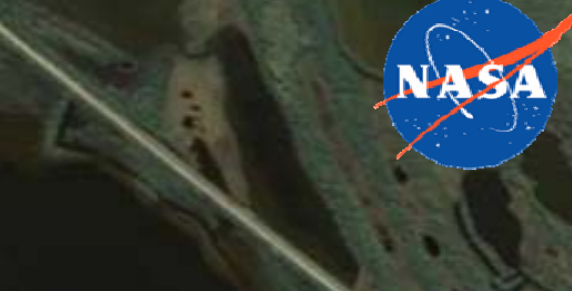
gunch

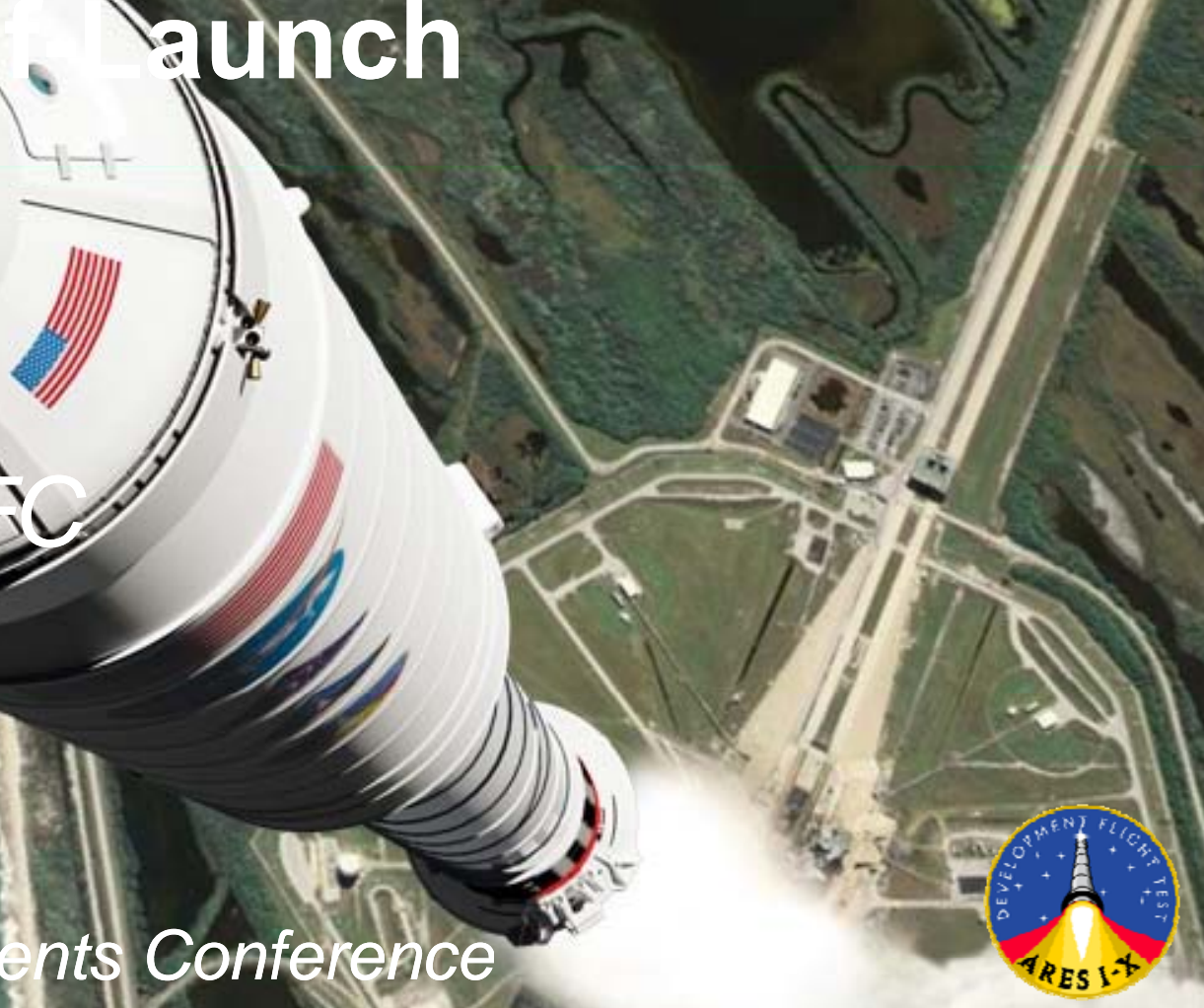
June 20-23 2009 


\section{Introduction}

- On the day-of-launch:

- Upper-air wind data is required to support evaluation of Ares I-X ascent Guidance, Navigation, and Control (GN\&C) and Loads parameters

- Wind data must be validated

- The purpose of this presentation is to show:

- Roles of each center

- Cape Canaveral Air Force Station (CCAFS)

- Johnson Space Center (JSC)

- Kennedy Space Center (KSC)

- Langley Research Center (LaRC)

- Marshall Space Flight Center (MSFC)

- Data sources and methods of transfer

- Methods for voice communications

- Countdown timeline 


\section{Concept}

- Ares I-X Ascent Dynamics Lead (ADL) [LaRC Ares I-X Systems Engineering and Integration support] will be at KSC Hangar AE

- Winds aloft will be validated by Marshall Natural Environments (NE) at the MSFC Huntsville Operations Support Center (HOSC) in the Meteorological Interactive Data Display System (MIDDS) Room

- JSC will provide an independent verification and validation function at Hangar AE with support from JSC Mission Control Center (MCC)

- The JSC Spaceflight Meteorology Group (SMG) will provide an upper-air winds forecast from the MCC

- Voice communications will be available on a direct Digital Voice Intercommunications System (DVIS) circuit between the HOSC, the MCC, and Hangar AE during the countdown. Phone lines can be used for backup.

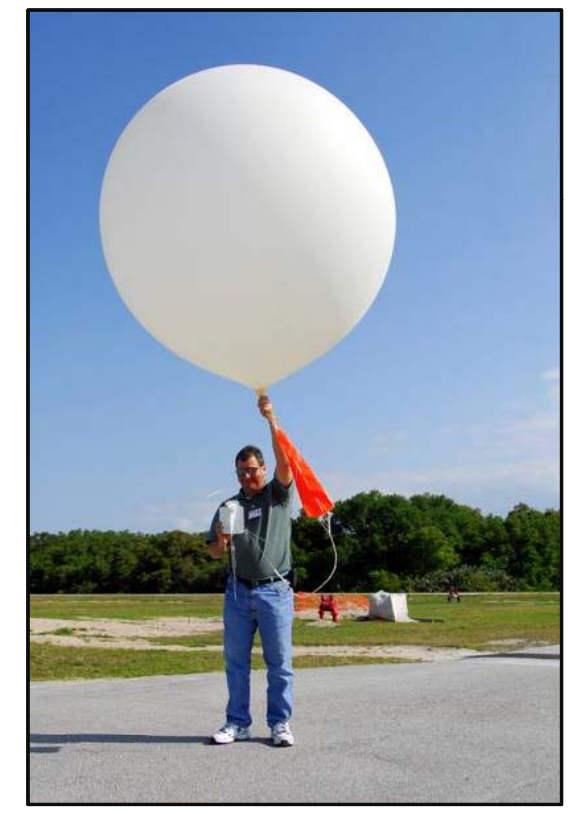

JACOBS 


\section{Concept}

- On-console time: L-7:00

- A preliminary evaluation of upper-level atmospheric conditions will be needed at L-4:30 to support a management decision to "proceed with countdown"

- LRFE 1 wind and density profile

- SMG forecast

- The launch countdown will begin at L-4:00 hours

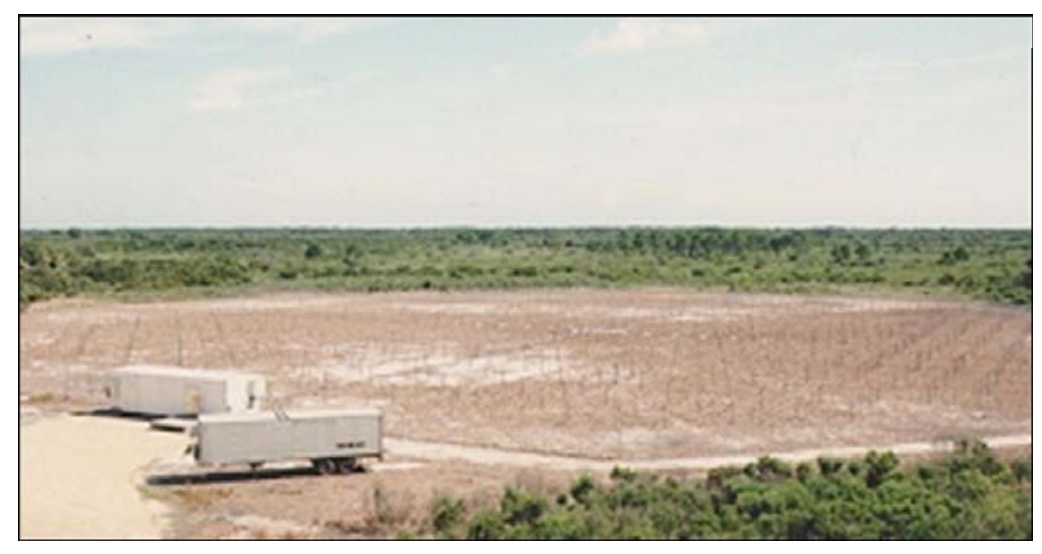

50 MHz Doppler Radar Wind Profiler 


\section{Proposed Ares I-X Day-of-Launch Upper-Air Wind Monitoring Schedule}

^ Low Resolution Flight Element (LRFE) Density to $80 \mathrm{kft}(25 \mathrm{~km})$ (Flight Duration 90 minutes)
* Low Resolution Flight Element (LRFE)

$$
\text { Winds to } 65 \mathrm{kft}(20 \mathrm{~km})
$$

(Flight Duration $\sim 70$ minutes)
\# High Resolution Flight Element (HRFE)

Winds to $50 \mathrm{kft}(15 \mathrm{~km})$

(Flight Duration $\sim 60$ minutes)

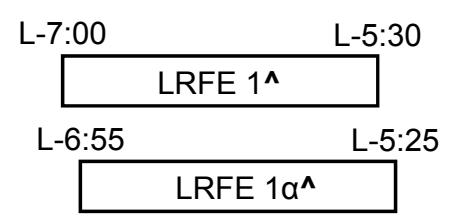

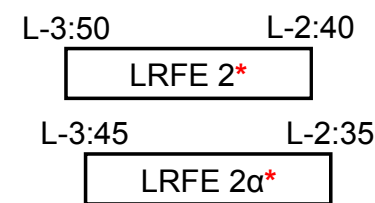

$\mathrm{L}-2: 50$

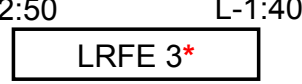

$\mathrm{L}-2: 45$ LRFE $3 \alpha^{*}$

$\mathrm{L}-1: 50$
SMG Upper-Air

Wind Forecast

$\mathrm{L}-4: 45$

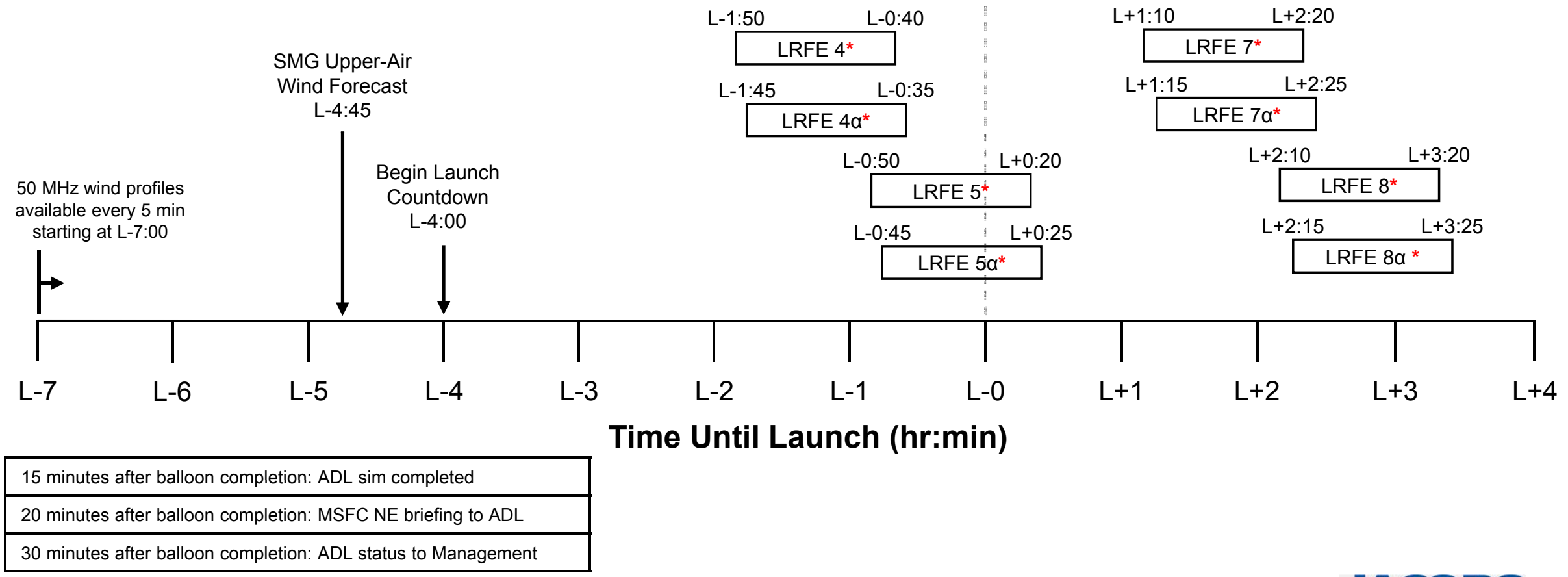

$L-0: 30$
HRFE 1\#

$\mathrm{L}-0: 25 \quad \mathrm{~L}+0: 35$

HRFE $1 \alpha^{\#}$

$L+0: 10 \quad L+1: 20$

$L+0: 15 \quad L+1: 25$

LRFE $6 \alpha^{*}$

Time Until Launch (hr:min) 


\section{Data Sources}

- 50 MHz Doppler Radar Wind Profiler (DRWP)

- Wind profiles available every 5 minutes starting at L-7:00

- Data collected from 6.6 kft [2 km] - $61 \mathrm{kft}[18.6 \mathrm{~km}]$ in $150 \mathrm{~m}$ [500 ft] intervals

- Used as comparison with balloon data

\section{- LRFE 1/1a}

- Provides winds and density (temperature, humidity and pressure) in $100 \mathrm{ft} \mathrm{[30}$ $\mathrm{m}]$ intervals

- Surface - $80 \mathrm{kft}[25 \mathrm{~km}]$

- Used for wind forecast

- Upper-Air Wind Forecast

- Provided by JSC Spaceflight Meteorology Group at L-4:45

- Surface to $80 \mathrm{kft}$ [24 km]

- Valid for opening of the launch window

\section{- LRFE 2/2 $\alpha-8 / 8 \alpha$}

- Provides wind data in $100 \mathrm{ft}[30 \mathrm{~m}]$ intervals

- Surface - $65 \mathrm{kft}$ [20 km]

- Used for loads and trajectory analysis during countdown

- HRFE 1/1a

- Provides wind data in $100 \mathrm{ft}[30 \mathrm{~m}]$ intervals

- Surface - $50 \mathrm{kft}$ [15 km]

- Used for final meteorological profile 


\section{Ares I-X Countdown Timeline}

L-2 Day System Checkout

29-Jul-09 08:00 (EDT)

31-Jul-09 00:00 (EDT) L-7:00 LRFE 1 Release

$50 \mathrm{MHz}$ DRWP profiles begin

\begin{tabular}{|c|c|c|}
\hline 00:05 (EDT) & L- $6: 55$ & LRFE 1a Release \\
\hline 01:30 (EDT) & $L-5: 30$ & LRFE 1 Complete \\
\hline 01:35 (EDT) & $\mathrm{L}-5: 25$ & LRFE 1a Complete \\
\hline 02:15 (EDT) & L- $4: 45$ & $\begin{array}{l}\text { SMG upper-air wind forecast } \\
\text { ADL sim complete }\end{array}$ \\
\hline 02:25 (EDT) & L-4:35 & $\begin{array}{l}\text { MSFC Natural Environments } \\
\text { briefing to Ascent Dynamics } L\end{array}$ \\
\hline 02:30 (EDT) & $\mathrm{L}-4: 30$ & ADL status to Management \\
\hline 03:00 (EDT) & $\mathrm{L}-4: 00$ & Begin Launch Countdown \\
\hline 03:10 (EDT) & $L-3: 50$ & LRFE 2 Release \\
\hline 03:15 (EDT) & L-3:45 & LRFE $2 \alpha$ Release \\
\hline 04:10 (EDT) & $L-2: 50$ & LRFE 3 Release \\
\hline 04:15 (EDT) & L-2:45 & LRFE 3a Release \\
\hline
\end{tabular}

04:20 (EDT) L- 2:40 LRFE 2 Complete

04:25 (EDT) L-2:35 LRFE $2 \alpha$ Complete

04:35 (EDT) L- 2:25 ADL sim complete

04:40 (EDT) L-2:20 MSFC NE briefing to ADL

04:50 (EDT) L-2:10 ADL status to Management

05:10 (EDT) L- 1:50 LRFE 4 Release

05:15 (EDT) L- 1:45 LRFE 4a Release

05:20 (EDT) L- 1:40

LRFE 3 Complete

05:25 (EDT) L- 1:35

LRFE 3a Complete

05:35 (EDT) L-1:25 ADL sim complete

05:40 (EDT) L- 1:20 MSFC NE briefing to ADL

05:50 (EDT) L-1:10 ADL status to Management

06:10 (EDT) L- 0:50 LRFE 5 Release 


\section{Ares I-X Countdown Timeline}

CONSTELLATION

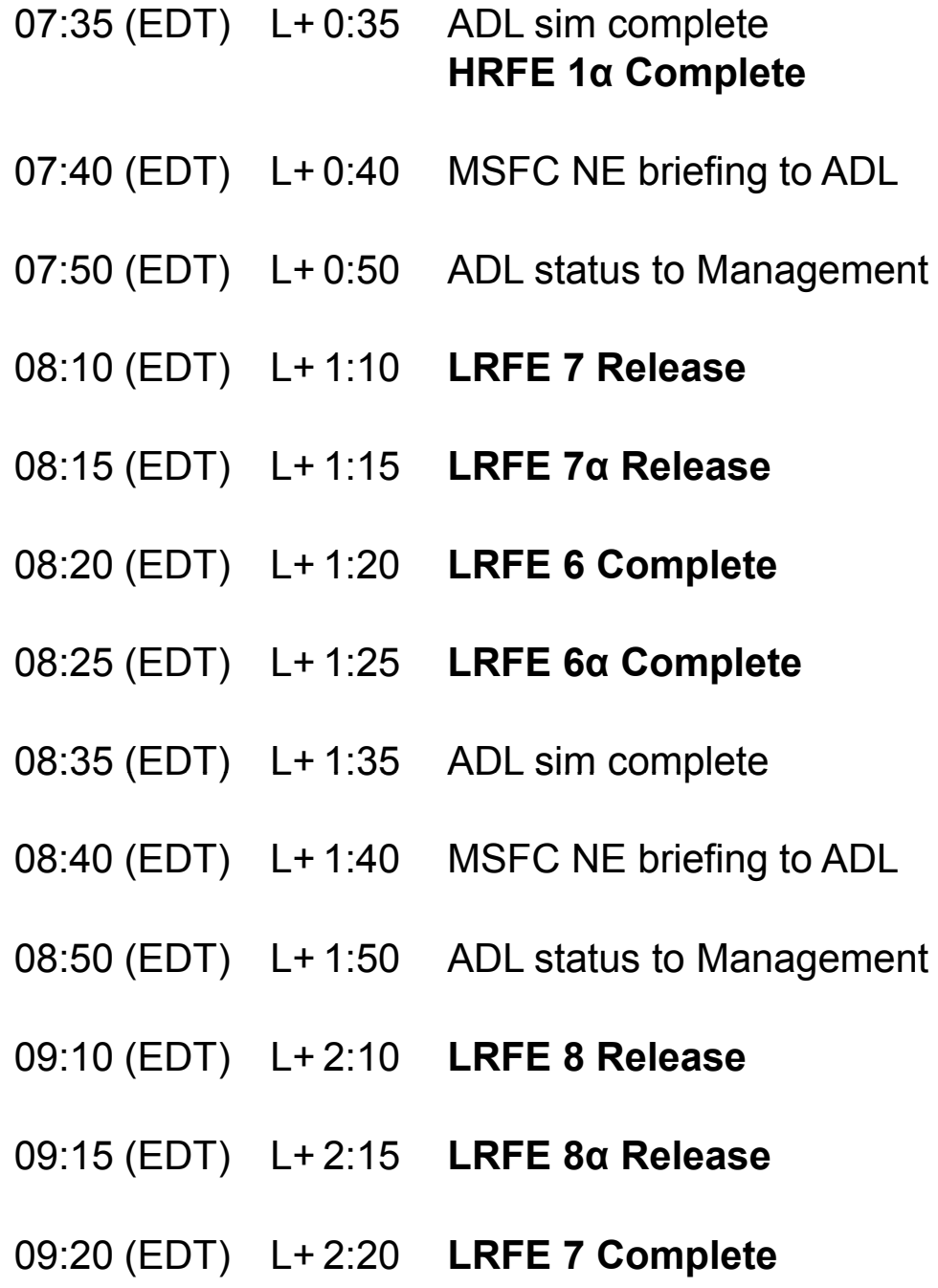




\section{Ares I-X Countdown Timeline}

\begin{tabular}{|c|c|c|}
\hline 09:25 (EDT) & $L+2: 25$ & LRFE 7a Complete \\
\hline 09:35 (EDT) & $L+2: 35$ & ADL sim complete \\
\hline 09:40 (EDT) & $L+2: 40$ & MSFC NE briefing to ADL \\
\hline 09:50 (EDT) & $L+2: 50$ & ADL status to Management \\
\hline 10:20 (EDT) & $L+3: 20$ & LRFE 8 Complete \\
\hline 10:25 (EDT) & $L+3: 25$ & LRFE $8 \alpha$ Complete \\
\hline 10:35 (EDT) & $L+3: 35$ & ADL sim complete \\
\hline 10:40 (EDT) & $L+3: 40$ & MSFC NE briefing to ADL \\
\hline 10:50 (EDT) & $L+3: 50$ & ADL status to Management \\
\hline 11:00 (EDT) & $L+4: 00$ & Close of 4-hour launch window \\
\hline
\end{tabular}




\section{Data Flow}

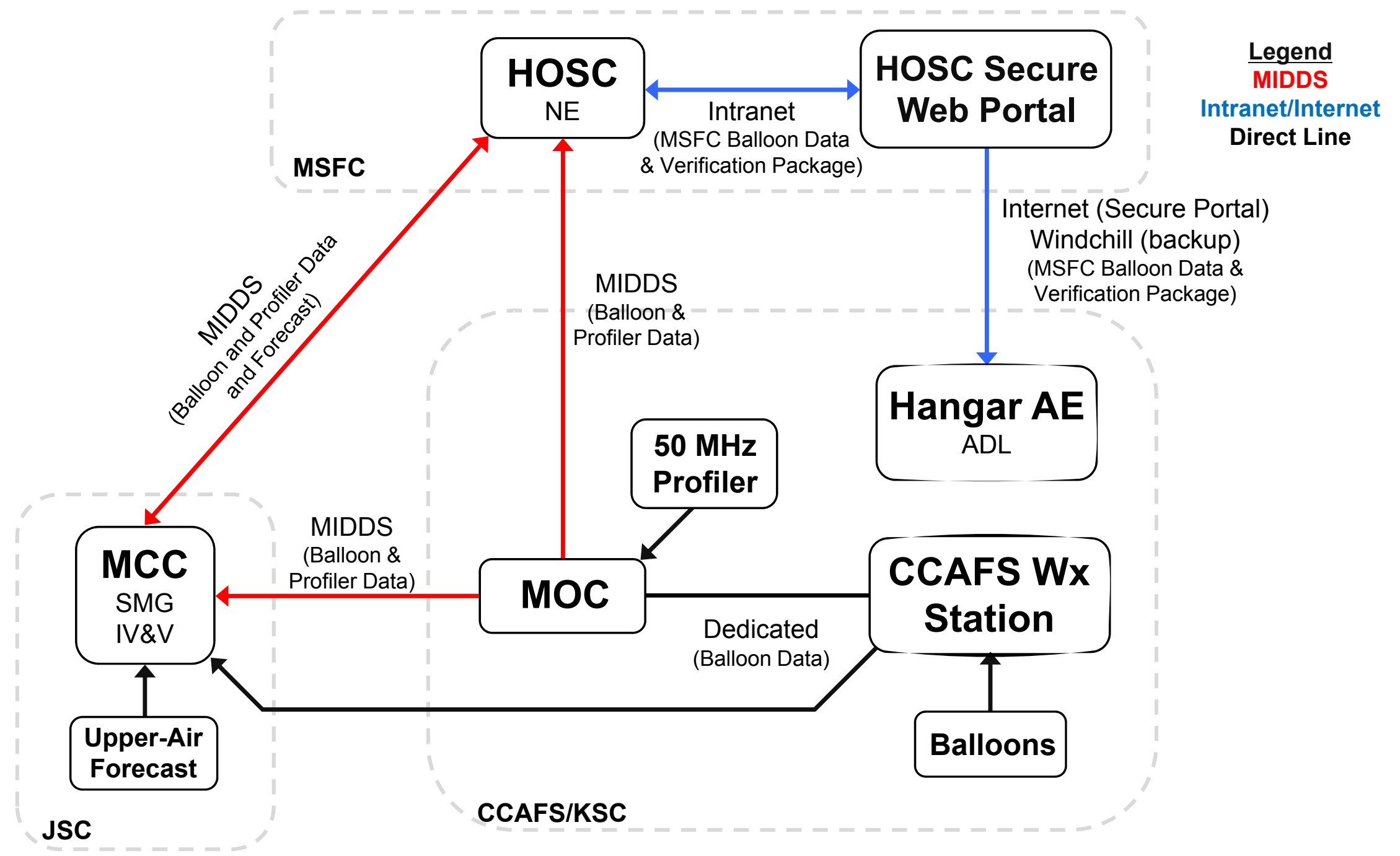




\section{Voice Communication Circuits (DVIS)}

\section{Launch Day}

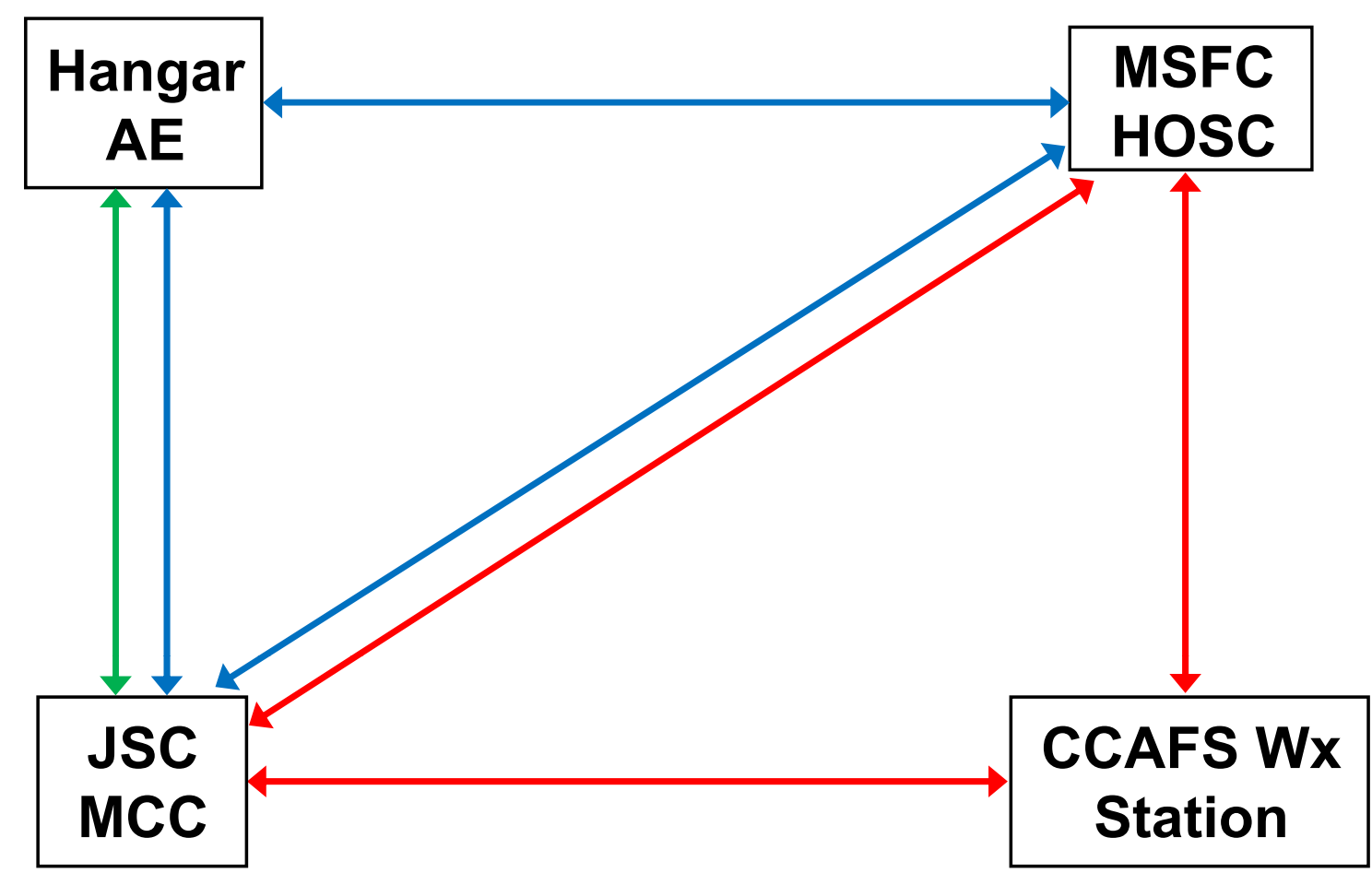

Legend

Landing Field Prime 2 (LFP2)

* All circuits will have monitor and talk capability Day-of-Launch I-Loads Update (DOLILU)

Shuttle Weather Coord 


\section{Simulations}

\section{- Ascent Dynamics Countdown (ADC) Simulations}

- ADC Sim 1

- 9 June 2009 (L-7:00 to L-1:00)

- Includes live \& recorded balloon data

- $50 \mathrm{MHz}$ DRWP data

- SMG Forecast

- ADL Location: LaRC

- ADC Sim 2

- Mid July 2009 (L-7:00 to $L+1: 00)$

- Includes live balloon data

- $50 \mathrm{MHz}$ DRWP data

- SMG Forecast

- ADL Location: LaRC

- ADC Sim 3

- Early August 2009 (L-7:00 to L+1:00)

- Includes live balloon data

- $50 \mathrm{MHz}$ DRWP data

- SMG Forecast

- ADL Location: Hanger AE 


\section{Voice Communication Circuits (DVIS) ADC Sims 1 \& 2}

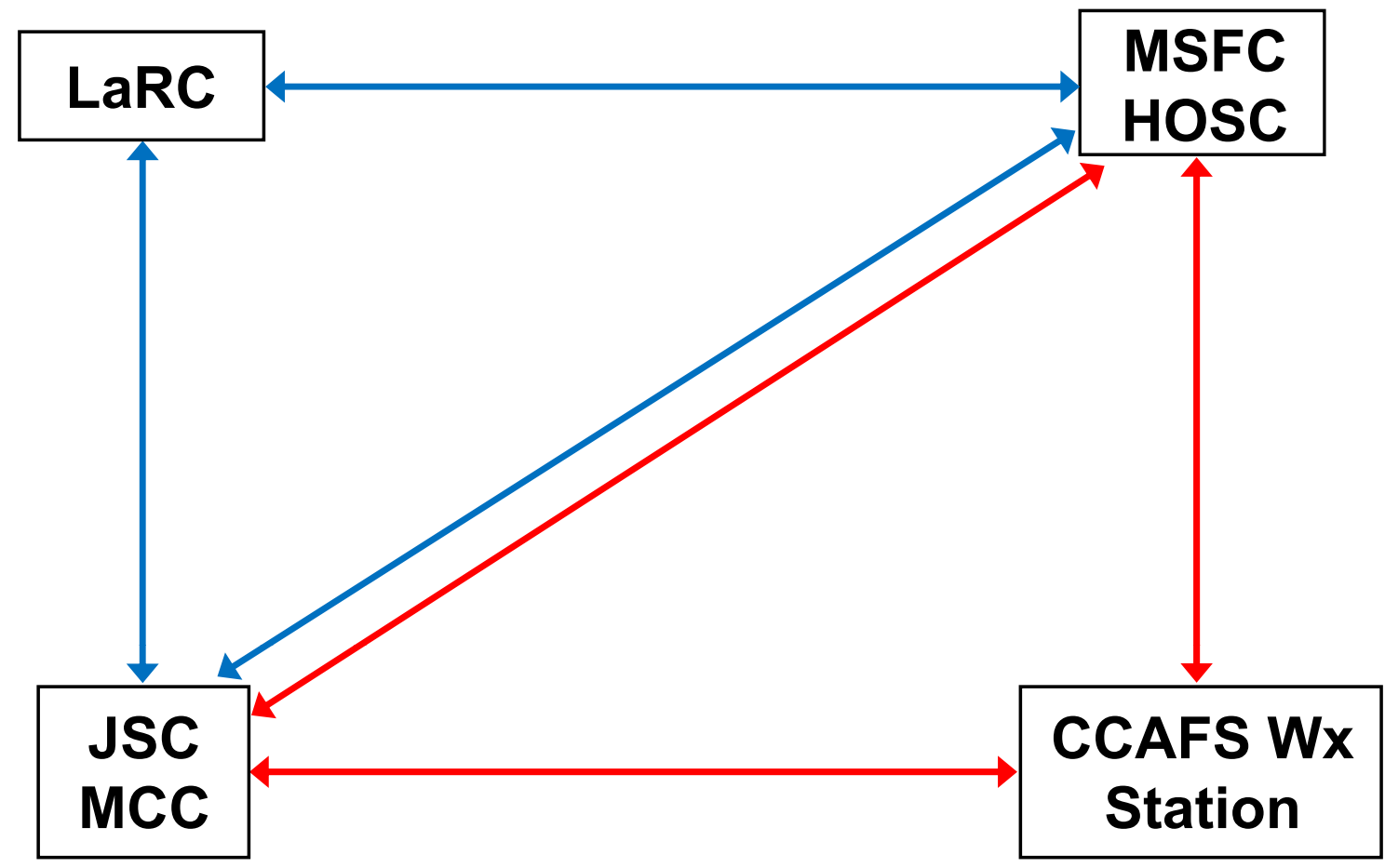

${ }^{*}$ All circuits will have monitor and talk capability 


\section{Simulations}

- Two full-up Ares I-X launch countdown simulations are planned prior to launch day.

- August 2009

- Will include live balloon data

- $50 \mathrm{MHz}$ DRWP data

- SMG Forecast

- ADL Location: Hangar AE

- The Ares I-X launch is currently planned for no earlier than 30 August 2009. 


\section{Backup Slides}




\section{Data Provided by Marshall Natural Environments}

\section{- Consensus plots}

- Used to verify that wind data provided from balloons from the $45^{\text {th }}$ Weather Squadron are acceptable for loads/trajectory evaluations

\section{- Climatology plots}

- Used to verify winds aloft are within the monthly $95 \%$ envelopes derived from the Earth Global Reference Atmospheric Model (GRAM) 2007 (contains 2006 Cape Canaveral Range Reference Atmosphere) winds/density profiles used in Monte Carlo trajectory simulations
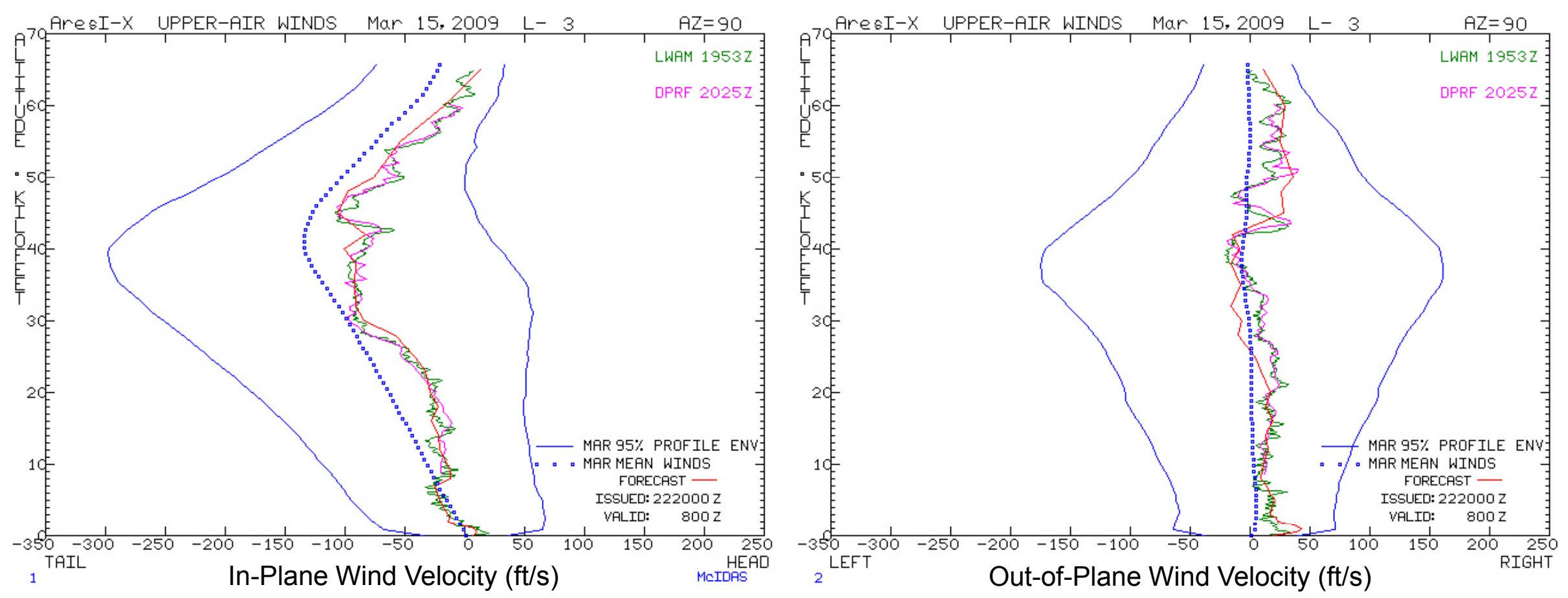

JACOBS 